\title{
Lyophilisate for Oral Suspension Dosage
} Form

National Cancer Institute

\section{Source}

National Cancer Institute. Lyophilisate for Oral Suspension Dosage Form. NCI Thesaurus.

Code C149640.

Solid preparation for veterinary use consisting of a freeze-dried powder intended to be dispersed in the specified liquid to create an oral suspension. 